This item was submitted to Loughborough's Research Repository by the author.

Items in Figshare are protected by copyright, with all rights reserved, unless otherwise indicated.

\title{
A kinetic and kinematic comparison of the two-footed and step-out back handsprings on the balance beam
}

PLEASE CITE THE PUBLISHED VERSION

https://doi.org/10.1080/14763141.2020.1849379

\section{PUBLISHER}

Taylor \& Francis (Routledge)

VERSION

AM (Accepted Manuscript)

\section{PUBLISHER STATEMENT}

This is an Accepted Manuscript of an article published by Taylor \& Francis in Sports Biomechanics on 11 Jan 2021, available online: http://www.tandfonline.com/10.1080/14763141.2020.1849379.

LICENCE

CC BY-NC-ND 4.0

\section{REPOSITORY RECORD}

Ede, Carlie, Fred Yeadon, and Michael Hiley. 2021. "A Kinetic and Kinematic Comparison of the Two-footed and Step-out Back Handsprings on the Balance Beam". Loughborough University. https://hdl.handle.net/2134/13379519.v1. 
Sports Biomechanics, ${ }^{* \star},{ }^{* \star * *}{ }_{-}^{* \star * *}, 2020$

\title{
A kinetic and kinematic comparison of the two-footed and step-out back handsprings on the balance beam
}

\author{
${ }^{1}$ Carlie Ede, ${ }^{1}$ Maurice R Yeadon and ${ }^{1}$ Michael J Hiley
}

${ }^{1}$ School of Sport, Exercise and Health Sciences, Loughborough University, Leicestershire, LE11 3TU, UK

\begin{abstract}
The back handspring is one of the most commonly performed skills on the balance beam in women's gymnastics. Despite this, quantitative research on the beam has often been overlooked. This study aimed to investigate the kinetic and kinematic variables during the performance of two back handspring techniques on the beam: the back handspring with two footed landing and the back handspring step-out. A modified balance beam was fixed to a force plate with an isolated mat for landing to allow analysis of the take-off and hand contact phases. Kinetic and kinematic data were recorded for twelve gymnasts performing both techniques. No statistically significant differences between techniques were found during take-off. However, average peak vertical and horizontal ground reaction forces (4.1 bodyweights $\pm 1.1 \mathrm{BW}$, and $0.7 \mathrm{BW} \pm 0.2 \mathrm{BW}$, respectively) were higher and time to peak force shorter during the hand contact phase for the two footed variant. A more vertical trajectory, along with a greater hand contact ground reaction force were found in comparison to the back handspring performed on the floor. These results highlight the need for more specific investigation to understand the factors which could contribute to reducing the load faced during balance beam performance.
\end{abstract}

Keywords: gymnastics; ground reaction forces; biomechanics

\section{INTRODUCTION}

The balance beam is one of four pieces of apparatus within Women's Artistic Gymnastics, where gymnasts are required to perform a range of acrobatic and dance elements. The balance beam itself measures $5.00 \mathrm{~m}$ long, $0.10 \mathrm{~m}$ wide, and $1.25 \mathrm{~m}$ high. The width of the beam requires the gymnast to stagger the hands and feet during contact, a restriction which alters the gymnasts' technique and reduces the effectiveness of the take-off from the narrow surface (McLaughlin, Geiblinger \& Morrison, 1995). During the 2009 Junior European Gymnastics Championships the back handspring was performed in $96 \%$ of balance beam routines (Miletic, Kalinski \& Bozanic, 2011), making it one of the most commonly performed skills within Women's Artistic Gymnastics (Penitente \& Merni, 2011). It is also, however, the most frequent skill associated with any type of injury (Lindner \& Caine, 1990; Singh, Smith, Fields \& McKenzie, 2008). The alternation of upper and lower limb support is a unique characteristic of Artistic Gymnastics, with the upper limbs commonly used as a point for weight bearing (Amaral, Claessens, Ferreirinha \& Santos, 2011; DiFiori, Puffer, Mandelbaum \& Mar, 1996). The anatomy of the wrist joint is poorly structured to cope with high impact forces and complete body weight support, with hyperextension of the wrists shown to intensify the forces which act through the distal radius and ulna (Davidson, Mahar, Chalmers \& Wilson, 2005; McLaren, Byrd, Herzog, Polikandriotis \& Wilimom, 2015). However, the magnitude of forces produced on the balance beam, which may increase the risk of injury, is currently unknown.

Two main variants of the back handspring are performed on the balance beam, where the gymnast jumps backwards to contact the beam with the hands (Federation Internationale De Gymnastique, 2017, pp. 136-137). From here the gymnast's legs can remain together through a second flight phase for a two footed landing (TF) (Figure 1a) or can separate into a split to land one foot at a time into a lunge, referred to as the back handspring step-out (SO) (Figure 1b). The SO is most commonly seen as the 
initial skill of an acrobatic sequence or performed in combination with dance elements to increase the difficulty value of the gymnast's routine. The TF on the other hand, is thought to resemble the back handspring on the floor exercise, which often precedes a somersault or dismount element, with the aim to increase the horizontal momentum and produce a strong vertical take-off (Koh, Grabiner \& Weiker, 1992; Penitente \& Merni, 2011; Sands \& McNeal, 2006). Despite its popularity, limited research has been conducted on the back handspring, especially in relation to the balance beam (Miletic et al., 2011; Penitente \& Merni, 2011; Sands, Caine \& Borms, 2003).
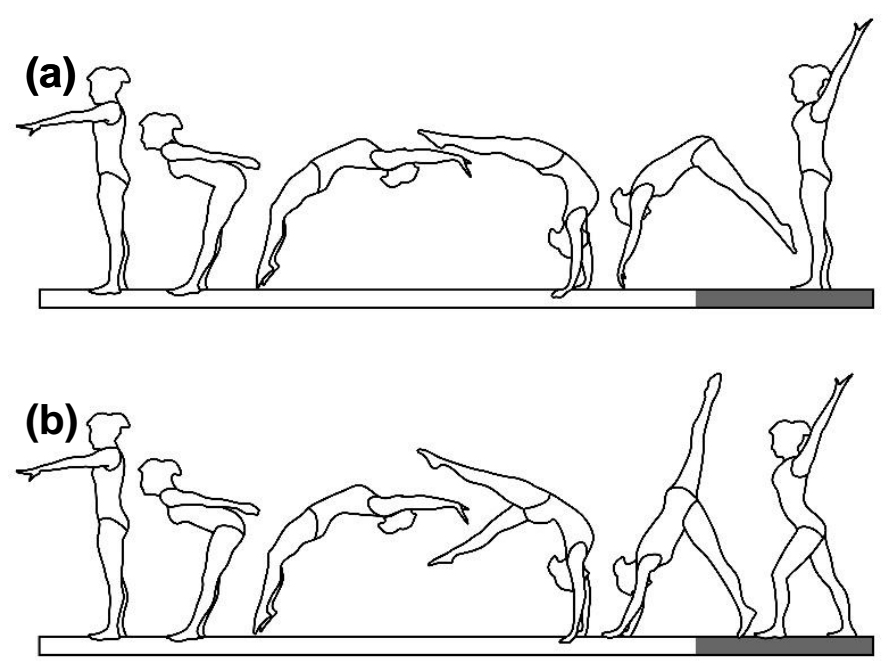

Figure 1. Key stages in the back handspring with (a) two-footed landing (TF) and (b) step-out (SO). The shaded area of the beam indicates that in the present study the gymnasts finished the skill on a landing mat.

Skilled performance of the back handspring on the balance beam has often been characterised by a more fixed and extended joint position through the wrists and elbows, with joint flexion resulting in a deduction to the gymnasts' score (Federation Internationale De Gymnastique, 2017). However, this lack of joint flexion may also increase the loading and risk of injury to the upper limbs (DiFiori et al., 2006; Farana et al., 2014; Sands \& McNeal, 2006; Webb \& Rettig, 2008). To date no research has effectively quantified this load. Additionally, as the elements performed on the balance beam can also be performed on the floor exercise, they are often assumed to be similar in nature (Sands et al., 2003). Given the clear differences in performance requirements such assumptions may be incorrect.

Kinetic and kinematic research on the balance beam is scarce. Wilkerson (1978) was able to record the performance of the SO on a balance beam instrumented with a strain gauge system although only analysis of the take-off from the feet was performed. Given the common nature of the skill and the high repetition within gymnastics training, improving the understanding of balance beam performance is critical for both injury prevention and gymnastics performance. The present study therefore aims to identify and compare the kinetics and kinematics of two commonly performed back handspring variants (TF and SO) on the balance beam, as well as allowing comparison with previous literature values on the floor exercise. It is hypothesised that the TF landing will require a greater vertical velocity and horizontal trajectory at foot take-off, and greater ground reaction force (GRF) and shorter contact time during hand contact to perform the second flight phase compared to the SO. It is also expected that differences will be seen between the back handspring on the balance beam and floor exercise. 


\section{METHODS}

A priori sample size calculation revealed that 12 participants were required to give a sufficiently large effect size (>0.8, Cohen, 1992) and power (>0.8). As a result, 12 female gymnasts (age: $21.0 \pm 3.1$ years, height: $159.3 \pm 3.4 \mathrm{~cm}$, mass: $56.7 \pm 5.8$ $\mathrm{kg}$ ) participated in the study following informed consent and university ethical approval. On average the participants had 15.4 years $( \pm 4.2$ years) of gymnastics experience. All participants, who were able to successfully perform and compete both the TF and SO on a competition standard balance beam, were active members of their university gymnastics team with national and international competition experience. On arrival gymnasts completed a self-selected warm up similar to that of their normal training, before completing five successful trials of both the TF and SO. All trials were evaluated by a qualified gymnastics coach and only deemed successful if completed without stepping or loss of balance.

A modified balance beam ( $1.83 \mathrm{~m}$ long, $0.18 \mathrm{~m}$ high, $0.10 \mathrm{~m}$ wide) (The Beam Store, 2014) was bolted to the surface of a $1200 \mathrm{~mm} \times 600 \mathrm{~mm}$ AMTI force plate (model BP6001200-4000, Advanced Mechanical Technology, Inc., Newton, MA, USA) recording at $1000 \mathrm{~Hz}$ (Figure 2). Sagittal plane motion was recorded with a Panasonic Lumix DMC-FZ200 camera (Panasonic, Osaka, Japan) positioned $5.25 \mathrm{~m}$ from the movement plane recording at $200 \mathrm{~Hz}$. The video and force data were synchronised with a LED light bank positioned within the field of view connected to an external trigger linked with the force plate. A 6-point calibration frame was placed within the movement plane and was recorded after each testing session. A landing mat of the same height as the beam was positioned at the end of the beam (Figure $1 \& 2$ ). The participants were instructed to begin with their feet on the beam, above the force plate, and perform the skill so that their hands would contact the beam, and their feet would finish on the landing mat rather than the beam to enable the hand contact to be isolated for force measurement.

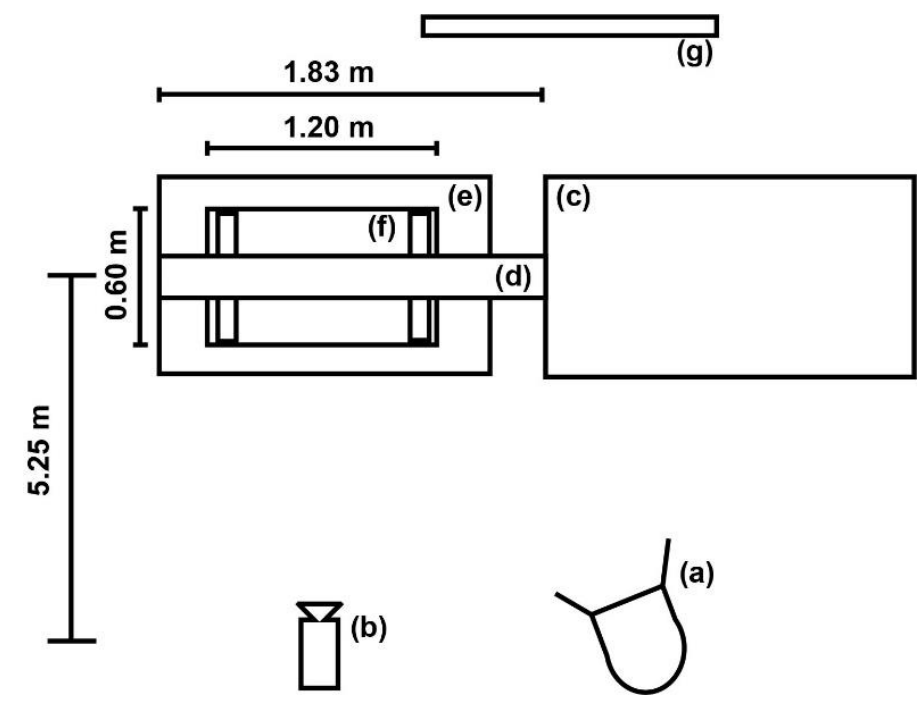

Figure 2. Plan view of the experimental set up used for data collection, with a) lighting, b) high speed video camera, c) landing mat, d) balance beam, e) safety matting, f) force plate, and g) timing.

For each trial the peak vertical $(F z)$ and anterior-posterior horizontal (Fy) force during the take-off and hand contact were identified and normalised to body weight $(B W)$, along with the time to peak Fz. The flight time, from feet to hands, and hand contact time were also determined from the force trace. Body weight was subtracted from the vertical force trace and the horizontal and vertical impulse was calculated as 
the area under the curve using the trapezoidal rule. Take-off impulse was calculated from the beginning of the recording to the point of take-off. Given that the participant begins in a stationary position, impulse was then divided by mass to calculate the vertical and horizontal velocities at foot take-off.

Take-off and hand contact were identified on the video and these frames were manually digitised using 21 body landmarks; mid-head (ear canal), 7th cervical vertebra/1st thoracic vertebra, 12th thoracic vertebra/1st lumbar vertebra and the joint centres of the shoulder, elbow, wrist, 2nd knuckle of third finger, hip, knee, ankle, toe, and ball of foot of the right and left sides of the body. Segmental centre of mass (CoM) and whole-body CoM was determined using segmental parameters from Dempster's data provided by Winter (1990). Take-off (TO) angle was calculated at the instant of toe-off as the angle formed between the line joining the toe to the CoM, and the horizontal. Touchdown (TD) angle was calculated at the instant of hand contact with the beam as the angle formed between the line joining the mid-point between the left and right wrist to the CoM, and the horizontal.

Mean values of each of the 5 trials for all participants were calculated and used for statistical analysis. The average coefficient of variation across the variables analysed was small (6\%; Tables $1 \& 2)$, suggesting that taking the mean of the five trials was representative of the gymnasts' performances. Tests of normality (ShapiroWilks) revealed that the data was normally distributed. Given the directional hypothesis, 1-tailed paired t-tests were used to assess the differences in Fz and Fy during take-off and hand contact, time to peak Fz, flight time, contact time, horizontal and vertical velocities and TO and TD angles between the two back handspring variants. To reduce the risk of type 1 error from multiple comparisons, the results of the t-test were adjusted using a Holm's correction (Ludbrook, 1998). The significance value was set at $p \leq 0.05$ and Cohen's $d$ was used to calculate the effect size (trivial $=$ $0.00-0.19$, small $=0.20-0.49$, medium $=0.50-0.79$ and large $>0.80$, according to Cohen, 1992). All data was processed using a custom Matlab script (2018a, Mathworks Inc. MA, USA).

In order to compare kinetic and kinematic variables for the back handspring performed on the beam (TF) and on the floor from a standing start, one sample t-tests using literature values from floor performances (Huang \& Hsu, 2009; Kampschroeder, Zebras \& Spina, 1997) were carried out. The two sources of literature values were chosen to cover the range of variables recorded in the present study. Again, the significance value was set at $p \leq 0.05$ and Holm's correction (Ludbrook, 1998) was applied.

\section{RESULTS}

No difference was observed between the take-off of the TF and SO on the balance beam (Table 1). However, peak Fz and Fy were found to be significantly greater $(p<0.027)$ during the hand contact of the TF compared to the SO, with mean peak values of 4.11 vs $3.43 \mathrm{BW}$ and $0.71 \mathrm{vs} 0.50 \mathrm{BW}$, respectively (Table 2). The higher vertical peak force values during hand contact in the TF was also associated with a shorter time to peak $(p=0.053)$, and therefore greater rate of loading. Across all participants, the mean time to peak Fz was $4 \mathrm{~ms}$ shorter during the hand contact of the TF (Table 2). Example force traces for both the TF and SO of one participant are shown in Figure 3, with the horizontal GRF being positive in the direction of movement.

In contrast to the hypothesis, the horizontal and vertical velocities at take-off from the feet, flight times, and TO and TD angles revealed no difference between the TF and SO (Tables 1 and 2). The hand contact time (Table 2) on the other hand, was shown to be on average $85 \mathrm{~ms}$ shorter in the TF $(p=0.001)$. 
Table 1. Mean values ( \pm standard deviations, (coefficient of variation)), results of $t$-tests and effect sizes between TF and SO for variables measured during take-off

\begin{tabular}{lllrrl}
\hline Variable & \multicolumn{1}{c}{ TF } & \multicolumn{1}{c}{ SO } & $\mathrm{t}$ & $p^{+}$ & $d$ \\
\hline Peak Fz (BW) & $2.28 \pm 0.24(2)$ & $2.26 \pm 0.24(2)$ & 1.086 & 0.752 & 0.076 \\
Peak Fy (BW) & $0.91 \pm 0.14(4)$ & $0.91 \pm 0.13(4)$ & -0.100 & 0.461 & -0.009 \\
Vertical Velocity (m/s) & $1.02 \pm 0.12(6)$ & $0.99 \pm 0.20(11)$ & 0.596 & 1.000 & 0.187 \\
Horizontal Velocity (m/s) & $1.30 \pm 0.13(4)$ & $1.31 \pm 0.11(4)$ & -0.524 & 0.916 & -0.079 \\
TO angle $\left(^{\circ}\right)$ & $122 \pm 4(1)$ & $122 \pm 3(1)$ & 0.304 & 0.767 & 0.041 \\
Flight time $(\mathrm{s})$ & $182 \pm 21(4)$ & $187 \pm 23(5)$ & -1.271 & 0.689 & -0.237 \\
\hline
\end{tabular}

+ $p$ value adjusted with Holm's correction (Ludbrook, 1998)

Table 2. Mean values ( \pm standard deviations, (coefficient of variation)), results of t-tests and effect sizes between TF and SO for variables measured during hand contact

\begin{tabular}{llllll}
\hline Variable & \multicolumn{1}{c}{ TF } & \multicolumn{1}{c}{ SO } & t & $p^{+}$ & $d$ \\
\hline Peak Fz (BW) & $4.11 \pm 1.05(10)$ & $3.43 \pm 0.72(8)$ & 3.389 & $0.027^{*}$ & 0.747 \\
Peak Fy (BW) & $0.71 \pm 0.19(16)$ & $0.50 \pm 0.19(17)$ & 4.383 & $0.005^{*}$ & 1.123 \\
Time to peak Fz (ms) & $31 \pm 6(17)$ & $35 \pm 8(15)$ & -2.872 & 0.053 & -0.596 \\
TD angle $\left(^{\circ}\right)$ & $74 \pm 5(2)$ & $73 \pm 3(2)$ & 2.881 & 0.060 & 0.427 \\
Contact time (ms) & $392 \pm 60(5)$ & $477 \pm 61(3)$ & -6.916 & $0.001^{*}$ & -1.410 \\
\hline
\end{tabular}

* Significant difference between TF and SO: $p<0.05$

+ $p$ value adjusted with Holm's correction (Ludbrook, 1998)

Table 3. Mean values ( \pm standard deviations), results of one sample t-tests and effect sizes between TF and floor exercise (FX) for variables measured during take-off and hand contact

\begin{tabular}{cccccc}
\hline Variable & TF & FX & $\mathrm{t}$ & $p^{+}$ & $d$ \\
\hline Take-off & & & & & \\
Peak Fz (BW) & $2.28 \pm 0.24$ & $2.30 \pm 0.30^{\mathrm{a}}$ & -0.314 & 0.760 & -0.079 \\
Peak Fy (BW) & $0.91 \pm 0.14$ & $0.70 \pm 0.10^{\mathrm{a}}$ & 5.099 & $0.002^{*}$ & 1.698 \\
Vertical Velocity (m/s) & $1.02 \pm 0.12$ & $0.88 \pm 0.23^{\mathrm{a}}$ & 4.217 & $0.006^{*}$ & 0.777 \\
Horizontal Velocity (m/s) & $1.30 \pm 0.13$ & $1.76 \pm 0.32^{\mathrm{a}}$ & -12.515 & $0.001^{*}$ & -1.902 \\
Flight time (s) & $182 \pm 21$ & $220 \pm 20^{\mathrm{a}}$ & -6.379 & $0.001^{*}$ & -1.867 \\
Hand contact & & & & \\
Peak Rz (BW) & $4.15 \pm 1.00$ & $3.05 \pm 0.49^{\mathrm{b}}$ & 3.824 & $0.008^{*}$ & 1.402 \\
Contact time (ms) & $392 \pm 60$ & $338 \pm 63^{\mathrm{a}, \mathrm{b}}$ & 3.115 & $0.020^{*}$ & 0.878 \\
\hline
\end{tabular}

* Significant difference between TF and FX: $p<0.05$

$+p$ value adjusted with Holm's correction (Ludbrook, 1998)

a data from Huang \& Hsu (2009) $(n=8)$

b data from Kampschroeder et al. (1997) $(n=19)$ 
Compared to the literature values (Huang \& Hsu, 2009) for back handspring on floor, the peak vertical ground reaction forces during take-off from feet on the beam were similar (Table 3). On the other hand, the peak horizontal ground reaction force was larger (Table 3) on the beam. The vertical velocity at take-off from the feet was found to be significantly higher on the beam although the horizontal velocity was significantly lower (Table 3). Despite a significantly larger resultant peak force at hand contact for the back handspring on beam, the hand contact time was found to be longer (Table 3).

(a)
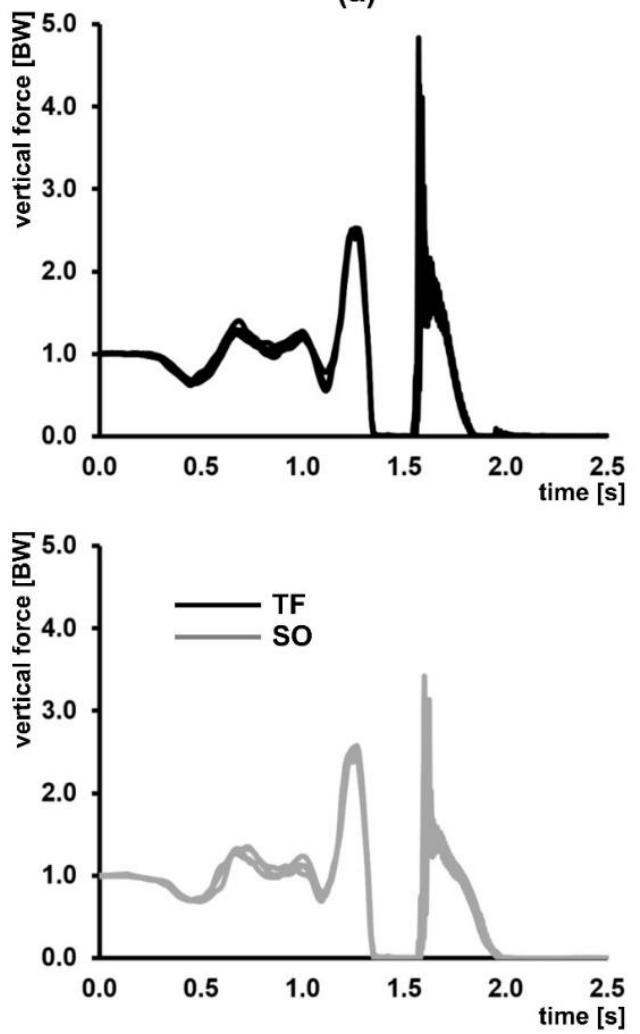

(b)
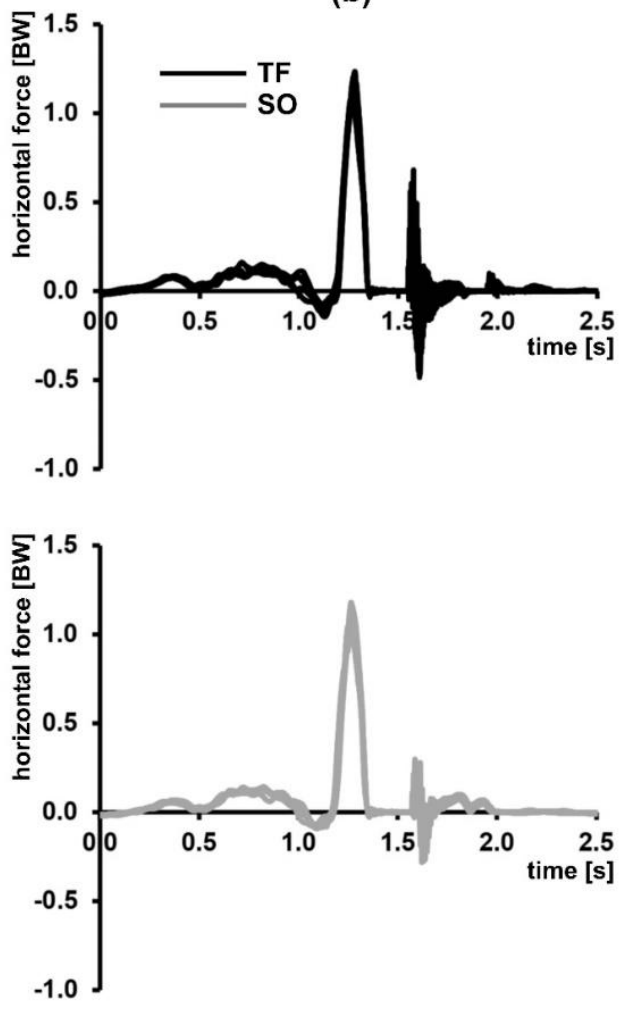

Figure 3. Typical (a) vertical and (b) horizontal ground reaction force traces for one participant performing five back handspring TF (black line) and five SO (grey line) synchronised at takeoff.

\section{DISCUSSION}

The primary aim of the study was to quantify the kinetic and kinematic variables of two commonly performed back handspring variants on the balance beam. It was hypothesised that differences would be observed between the two, with the TF having a more horizontal trajectory and greater GRF at take-off from the feet. However, following analysis, there was no significant difference in GRFs or CoM velocities between the two variants at take-off from the feet. Similarly, there were no statistically significant differences in the TO (from feet) and TD (hand contact) angles for the TF and SO, suggesting that the requirement to contact the balance beam with the hands at the end of the first flight phase has a strong influence on the initial movements of the skill. Statistically significant differences were found between the two variants for peak Fz, peak Fy and contact time during the hand contact phase, suggesting that this was the crucial phase differentiating the two variants (Table 2). 
Analysis of the kinetic and kinematic variables revealed no statistically significant differences between variables at take-off from the feet (Table 1). With mean peak Fz values of 2.28 BW (TF) and 2.26 BW (SO), and a mean peak Fy of $0.91 \mathrm{BW}$ recorded for both variants, the initial movements appear to be very similar. The peak force values recorded in the present study were much larger than previous kinetic measures on the balance beam of $1.68 \mathrm{BW}$ (vertical) and 0.84 BW (horizontal) (Wilkerson, 1978). However, in both balance beam studies (present study and Wilkerson, 1978) the vertical reaction force was larger than the horizontal reaction force. The difference in peak vertical reaction forces between the present study and that of Wilkerson (1978) may be due to the lower levels of experience ( 4.36 years \pm 1.71 years) of the gymnasts used in the previous research. Huang \& Hsu (2009) reported a mean peak vertical force of 2.3 BW in the take-off from floor comparable with the values in this study (2.28 BW and 2.26 BW). They also found a slightly lower value of $0.7 \mathrm{BW}$ in the horizontal direction than the present study (0.91 BW). Payne \& Barker (1976) also reported vertical and horizontal force data for a back handspring but the data was reported in $\mathrm{kg}$ rather than bodyweights and no participant mass data were reported. The peak vertical and horizontal forces during take-off from the feet were approximately $1870 \mathrm{~N}$ and $390 \mathrm{~N}$, respectively (Payne \& Barker, 1976).

There are other key differences between the back handspring performed on the balance beam and floor exercise. From a standing position Huang \& Hsu (2009) obtained CoM velocities of $0.88 \mathrm{~m} / \mathrm{s}$ (vertical) and $1.76 \mathrm{~m} / \mathrm{s}$ (horizontal) compared to the $1.02 \mathrm{~m} / \mathrm{s}$ (vertical) and $1.30 \mathrm{~m} / \mathrm{s}$ (horizontal) from the present study (Table 3). On the floor exercise, the back handspring aims to increase and maintain horizontal momentum (Koh et al., 1992; Sands \& McNeal, 2006), evident in a greater horizontal velocity. On the other hand, the back handspring on the balance beam exhibits a more vertical trajectory, evidenced by the greater vertical velocity at take-off (Table 3) possibly in order to ensure successful hand contact. A similar difference can be observed in the TO angle, with a more vertical TO angle on the beam, $122^{\circ}$ (Table 1), compared to the floor exercise, $132^{\circ}$ (Lovecchio et al., 2013). These results emphasise the different requirements when performing a back handspring on the floor and on the balance beam, such that they cannot be assumed to be equivalent. That is, on the beam a successful back handspring has tighter constraints on where the hands can be placed and greater consequences, due to the height of the beam above the floor, should this hand placement not be achieved.

The flight time from the feet to the hands showed no statistical difference between the TF and SO back handspring (Table 1). The flight times from both variants (182 ms and $187 \mathrm{~ms}$ ) were longer than those previously reported on the beam (141 $\mathrm{ms})$ by Wilkerson (1978). The flight times from both beam studies, however, were shorter than those reported for the back handspring on the floor, approximately 220 and $273 \mathrm{~ms}$, from a standing start and a round-off entry, respectively (Huang \& Hsu, 2009; Penitente \& Merni, 2011). Hand contact time on the beam was shown to be significantly shorter in the TF than the SO back handspring (Table 2). This is consistent with the requirements for a second flight phase from the hands to feet in the TF variant. In comparison to previous research on the floor exercise (Huang \& Hsu, 2009; Kampschroeder et al., 1997), contact times for both the TF and SO on the beam were found to be longer (Table 3), and especially so when compared to the back handspring from a round-off on floor (Penitente \& Merni, 2011). When performing a back handspring from a round-off the horizontal velocity at hand touchdown is greater and so having a long hand contact time would result in a large take-off angle. However, the longer hand contact time on the balance beam may act to assist performance by 
reducing the horizontal velocity and controlling the motion, given the need to finish the skill successfully without additional movement.

Although no difference was observed during the take-off, the hand touchdown of the TF was shown to produce a significantly greater peak vertical GRF than the SO, 4.11 BW vs. $3.43 \mathrm{BW}$, respectively (Table 2). The greater peak force may be linked with the requirement to produce a second flight phase in the TF since the greater peak vertical GRF may be expected to be associated with a greater vertical impulse. The duration of hand contact is presented in Table 2, the time from hand contact to subsequent foot contact indicated that on average there was a short flight phase for the TF (403 $\pm 41 \mathrm{~ms})$ and no flight phase for the SO $(349 \pm 61 \mathrm{~ms})$. Although the TF produced a greater peak force during hand contact than the $\mathrm{SO}$, both back handspring variants produced larger peak forces than those reported for the back handspring in the floor exercise (Table 3). Kampschroeder et al. (1997) reported resultant GRF of 3.05 BW during performances of the back handspring from a standing start when performed on the floor, which were significantly lower than on the beam. No mention of the force plate covering was made by Kampschroeder et al. (1997), only that the hands contacted the force plate, suggesting that this would be on a relatively harder surface than the beam. Koh et al. (1992) recorded similar values (2.37 BW) from a round-off entry, although this was defined as the compressive force which acted along the long axis of the forearm. These results are both lower than the $4.11 \mathrm{BW}$ (TF) and 3.43 BW (SO) reported in the current study. In contrast, Daly, Rich, Klein \& Bass (1999) reported comparable values of 3.6 BW during the hand contact of the round-off back handspring in young male gymnasts. The larger values found by Daly et al. (1999) are likely to be the result of the greater horizontal velocity of the back handspring from a round-off entry.

Flexion of the elbows has been suggested to decrease the maximal force and delay the time to peak force during contact, although, elbow flexion during skill execution would result in a deduction to the gymnast's score. Therefore, gymnasts are often instructed to maintain an extended joint position during the back handspring, possibly resulting in the higher reaction forces found (Chou et al., 2001; Cuk \& Marinsek, 2013; DiFiori et al., 2006; Koh et al., 1992). Kinematic data from the elbow was not collected in the present study and may warrant further investigation in the future. The stiffer surface of the balance beam may also be a contributing factor to the greater GRF seen during hand contact (McNitt-Gray, Yokoi \& Millward, 1994; Seegmiller \& McCaw, 2003). A comparison of CoM height during the hand contact phase for the two variations on the beam revealed no differences at touchdown, takeoff or change in height throughout contact, suggesting that the amount of elbow flexion or other actions, such as splitting the legs, does not appear to be the cause of the difference found in peak vertical force. While it could be argued that the use of Dempster's parameters might not be the most appropriate for female gymnasts, it should be recognised that the use of any inertia parameter set is likely to introduce some systematic offset in CoM height calculation but this would not affect the above result.

In addition to the vertical reaction forces during hand contact, a larger horizontal force was seen in the TF compared to the SO (Table 2). This places significant strain on the upper limbs, with large forces during contact shown to contribute to upper extremity injury (Farana, Jandacka, Uchytil, Zahradnik \& Irwin, 2017; Koh et al., 1992; Seeley \& Bressel, 2005). Given the higher loading found during the back handspring on the balance beam compared to the floor exercise, the risk of injury to the upper extremities should be of concern. Seeley \& Bressel (2005) examined the GRF of the upper extremities during the round-off phase of the Yurchenko vault (2.38 BW), noting 
the comparable nature of the reaction force to magnitudes capable of fracturing the distal radius. With a peak Fz of $4.11 \mathrm{BW}$ reported in the present study, these values have the potential to result in significant injury to the upper limbs. Troy \& Grabiner (2007) also highlighted a large decrease in the fracture load when the impact force was transmitted off axis, a factor which creates an even greater injury risk if the gymnast is 'off-line' or performs the skill incorrectly. Despite the hand TD angle (wrist to CoM angle) being similar between the two variations, closer inspection of the forearm angle at TD revealed a small but significant difference $\left(96^{\circ} \pm 3^{\circ}\right.$ vs $94^{\circ} \pm 2^{\circ}, p$ $=0.045$ including Holm's correction). The additional rotation of the forearm prior to contact may have contributed to the additional horizontal force in the TF.

Clear differences have been identified between the technique of the back handspring on the balance beam and the floor exercise, with the back handspring on the balance beam requiring a more vertical take-off and producing a larger reaction force during hand contact (Table 3). With this knowledge, coaches should ensure that throughout training they focus on the differences in skill execution to fulfil the requirements of the back handspring on beam. The similarity observed between the TF and SO during take-off from the feet highlights the strong influence the balance beam places on execution of the skill. Consequently, the take-off phase of the back handspring may be emphasised as a key aspect for successful performance and should therefore be a strong focus for coaching practice.

As it currently stands there appears to be a conflict between the requirements to successfully perform the back handspring on the balance beam and the repetitive loading faced by the gymnast. The high number of repetitions characteristic of balance beam performance (Burt, Naughton, Higham \& Landeo, 2010; Caine, Cochrane, Caine \& Zemper, 1989), along with the large reaction forces identified, highlight an area of concern within Artistic Gymnastics. From a coaching perspective, it is critical that coaches actively monitor the volume of training, especially of the basic skills, in addition to ensuring that the gymnast is physically prepared to withstand the large forces and repetitive loading of the back handspring on the balance beam.

When examining the results, it must be considered that although the participants began the skill on the balance beam, they were not required to land on it. Additionally, the balance beam was fixed to the force plate which may have affected its elasticity and responsiveness when compared to a competition standard balance beam. However, this was necessary to maintain the safety of the participants and ensure direct contact with the force plate. Of note, a competition standard balance beam does not have uniform stiffness, and skills performed toward the ends of a beam may also relate to the stiffer surface used in this study. These methods allowed the clear identification of the hand contact phase, a restriction which limited previous attempts of kinetic measures on the balance beam. To limit these effects, participants were only recruited if they could successfully complete the skill on a competition standard balance beam and were asked to replicate this performance.

\section{CONCLUSION}

Balance beam skills comprise an area of gymnastics research that can often be overlooked given the similarity of skill performance to the floor exercise. In contrast to the hypothesis, near identical take-off conditions were observed during the TF and SO, although as expected, the GRF during hand contact was greater in the TF variant. In comparison to previous literature on the floor exercise the results of the current study revealed a larger GRF during the hand contact and a more vertical trajectory of the centre of mass at take-off from the feet. These results suggest that the requirement to successfully contact the narrow surface of the balance beam has a strong influence on 
the skill performance. The large forces found also highlight the need for coaches to actively monitor the volume of training and ensure the physical preparation of the gymnast, in order to minimise the repetitive loading faced. With minimal research previously available, these results highlight the need for more specific investigation to understand the factors which could contribute to reducing the load faced during balance beam performance.

\section{REFERENCES}

Amaral, L., Claessens, A., Ferreirinha, J., \& Santos, P. (2011). Ulnar variance and its related factors in gymnasts: a review. Science of Gymnastics Journal, 3, 59-89.

Burt, L. A., Naughton, G. A., Higham, D. G., \& Landeo, R. (2010). Training load in prepubertal female artistic gymnastics. Science of Gymnastics Journal, 2, 5-14.

Caine, D., Cochrane, B., Caine, C., \& Zemper, E. (1989). An epidemiological investigation of injuries affecting young competitive female gymnasts. American Journal of Sports Medicine, 17, 811-820.

Chou, P. H., Chou, Y. L., Lin, C. J., Su, F. C., Lou, S. Z., Lin, C. F., \& Huang, G. F. (2001). Effect of elbow flexion on upper extremity impact forces during a fall. Clinical Biomechanics, 16, 888-894.

Cohen, J. (1992). A power primer. Psychological Bulletin, 112, 155-159.

Cuk, I., \& Marinsek, M. (2013). Landing quality in artistic gymnastics is related to landing symmetry. Biology of Sport, 30, 29-33.

Daly, R. M., Rich, P. A., Klein, R., \& Bass, S. (1999). Effects of high-impact exercise on ultrasonic and biochemical indices of skeletal status: A prospective study in young male gymnasts. Journal of Bone and Mineral Research, 14, 1222-1230.

Davidson, P. L., Mahar, B., Chalmers, D. J., \& Wilson, B. D. (2005). Impact modelling of gymnastics back handsprings and dive rolls in children. Journal of Applied Biomechanics, 21, 115-128.

DiFiori, J. P., Caine, D. J., \& Malina, R. M. (2006). Wrist pain, distal radial physeal injury, and ulnar variance in the young gymnast. The American Journal of Sports Medicine, 34, 840-849.

DiFiori, J. P., Puffer, J. C., Mandelbaum, B. R., \& Mar, S. (1996). Factors Associated with Wrist Pain in the Young Gymnast. The American Journal of Sports Medicine, 24, 9-14.

Farana, R., Jandacka, D., Uchytil, J., Zahradnik, D., \& Irwin, G. (2014). Musculoskeletal loading during the round-off in female gymnastics: the effect of hand position. Sports Biomechanics 13, 123-134.

Farana, R., Jandacka, D., Uchytil, J., Zahradnik, D., \& Irwin, G. (2017). The influence of hand positions on biomechanical injury risk factors at the wrist joint during the round-off skills in female gymnastics. Journal of Sports Sciences, 35, 124-129.

Federation Internationale De Gymnastique. (2017). 2017-2020 Code of Points Women's Artistic Gymnastics. FIG.

Huang, C., \& Hsu, G. S. (2009). Biomechanical Analysis of Gymnastic Back Handspring. Proceedings of the 27th International Conference on Biomechanics in Sports.

Kampschroeder, D., Zebras, C., \& Spina, M. (1997). A kinetic and kinematic comparison of skilled versus unskilled standing back handspring performances in young gymnasts. 15 International Symposium of Biomechanics in Sports.

Koh, T. J., Grabiner, M. D., \& Weiker, G. G. (1992). Technique and ground reaction forces in the back handspring. The American Journal of Sports Medicine, 20, 6166.

Lindner, K. J., \& Caine, D. J. (1990). Injury patterns of female competitive club 
gymnasts. Canadian Journal of Sport Sciences, 15, 254-261.

Lovecchio, N., Grassi, G., Shirai, Y. F., Galante, D., Grandi, G., Ferrario, V. F., \& Sforza, C. (2013). Kinematics of key technique variables in the backward handsprings of elite gymnasts. Revista Brasileira de Medicina Do Esporte, 19, 292-296.

Ludbrook, J. (1998). Multiple Comparison Procedures Updated. Clinical and Experimental Pharmacology and Physiology, 25, 1032-1037.

McLaren, K., Byrd, E., Herzog, M., Polikandriotis, J. A., \& Wilimom, S. C. (2015). Impact shoulder angles correlate with impact wrist angles in standing back handsprings in preadolescent and adolescent female gymnasts. The International Journal of Sports Physical Therapy, 10, 341-346.

McLaughlin, P. A., Geiblinger, H., \& Morrison, W. E. (1995). Take-off kinematics of beam dismounts. ISBS-Conference Proceedings Archive Vol. 1. No. 1.

McNitt-Gray, J. L., Yokoi, T., \& Millward, C. (1994). Landing strategies used by gymnasts on different surfaces. Journal of Applied Biomechanics, 10, 237-252.

Miletic, D., Kalinski, S. D., \& Bozanic, A. (2011). How does the performance of acrobatic elements effect final beam results in artistic gymnasts. 6th International Scientific Conference on Kinesiology Integrative Power of Kinesiology, 537-540.

Payne, A. H., \& Barker, P. (1976). Comparison of the take-off forces in the flic flac and the back somersault in gymnastics. Biomechanics VB, 314-321.

Penitente, G., \& Merni, F. (2011). Kinematic analysis of the centre of mass in the back handspring: A case study. The Gym Coach, 4, 1-11.

Sands, W. A., Caine, D. J., \& Borms, J. (2003). Scientific Aspects of Women's Gymnastics. Karger Medical and Scientific Publishers.

Sands, W. A., \& McNeal, J. R. (2006). Hand position in a back handspring (flic flac). Technique, 26, 8-9.

Seegmiller, J. G., \& McCaw, S. T. (2003). Ground reaction forces among gymnasts and recreational athletes in drop landings. Journal of Athletic Training, 28, 311314.

Seeley, M. K., \& Bressel, E. (2005). A comparison of upper-extremity reaction forces between the yurchenko vault and floor exercise. Journal of Sports Science and Medicine, 4, 85-94.

Singh, S., Smith, G. A., Fields, S. K., \& McKenzie, L. B. (2008). Gymnastics-related injuries to children treated in emergency departments in the United States, 19902005. Pediatrics, 121, e954-e960.

The Beam Store. (2014). 2.4m Tan Suede Low Profile Gymnastics Balance Beam. http://www.thebeamstore.co.uk/6-ft-tan-suede-low-profile-gymnastics-balancebeam-647

Troy, K. L., \& Grabiner, M. D. (2007). Off-axis loads cause failure of the distal radius at lower magnitudes than axial loads: a finite element analysis. Journal of Biomechanics, 40, 1670-1675.

Webb, B. G., \& Rettig, L. A. (2008). Gymnastics wrist injuries. Current Sports Medicine Reports, 7, 289-295.

Wilkerson, J. D. (1978). Kinematic and kinetic analysis of the back handspring in gymnastics as performed on the balance beam. Microform Publications, College of Health, Physical Education and Recreation, University of Oregon.

Winter, D. A. (2009). Biomechanics and Motor Control of Human Movement (4th ed.). John Wiley and Sons, Inc. 